\title{
Transition of cord blood lead level, 1985-2002, in the Taipei area and its determinants after the cease of leaded gasoline use
}

\author{
Yaw-Huei Hwang, ${ }^{\text {a,b,* }}$ Yi Ko, ${ }^{\mathrm{b}}$ Chien-Dai Chiang, ${ }^{\text {c,d }}$ Shih-Penn Hsu, ${ }^{\mathrm{c}, \mathrm{d}}$ Yu-Hsiang Lee, ${ }^{\mathrm{c}, \mathrm{d}}$ \\ Chun-Hsien $\mathrm{Yu}^{\text {e }}{ }^{\text {Chuen-Hua Chiou, }}{ }^{\mathrm{c}, \mathrm{d}}$ Jung-Der Wang, ${ }^{\mathrm{a}, \mathrm{f}}$ and Hung-Yi Chuang ${ }^{\mathrm{g}}$ \\ ${ }^{a}$ Institute of Occupational Medicine and Industrial Hygiene, College of Public Health, National Taiwan University, Taipei, Taiwan, ROC \\ ${ }^{\mathrm{b}}$ Department of Public Health, College of Public Health, National Taiwan University, Taipei, Taiwan, ROC \\ ${ }^{\mathrm{c}}$ Department of Obstetrics and Gynecology, Taipei Municipal Women and Children Hospital, Taipei, Taiwan, ROC \\ ${ }^{\mathrm{d}}$ Department of Nursing, Taipei Municipal Women and Children Hospital, Taipei, Taiwan, ROC \\ ${ }^{\mathrm{e}}$ Department of Pediatrics, Taipei Municipal Women and Children Hospital, Taipei, Taiwan, ROC \\ ${ }^{\mathrm{f}}$ Department of Internal Medicine, National Taiwan University Hospital, Taipei, Taiwan, ROC \\ ${ }^{\mathrm{g}}$ Department of Occupational Medicine, Kaohsiung Medical University Hospital, and School of Public Health, \\ Kaohsiung Medical University, Taiwan, ROC
}

Received 22 August 2003; accepted 4 February 2004

\begin{abstract}
Lead has long been of concern for its toxicity, impairment of neurobehavioral and cognitive development, and electrophysiological deficits in children, even at levels less than $10 \mu \mathrm{g} / \mathrm{dL}$. The present study was conducted to elucidate the extent of cord blood lead level decline in the Taipei area from 1985 to 2002 and to explore the factors affecting the cord blood lead level after the cease of leaded gasoline use. In the current study period of 2001-2002, 184 of 1310 newborns delivered in the Taipei Municipal Women and Children Hospital between September 2001 and August 2002 were eligible and randomly selected to participate in this study. Neither of their parents had an occupational lead exposure history. At each delivery, a sample of 5-10 mL umbilical cord blood was collected for lead determination by graphite furnace atomic absorption spectrometry. The cord blood lead level of the newborns in the current study period averaged $2.35 \pm 1.12 \mu \mathrm{g} / \mathrm{dL}$. Together with the cord blood lead averages of $7.48 \pm 2.25$ and $3.28 \pm 1.52 \mu \mathrm{g} / \mathrm{dL}$ obtained from two previous surveys conducted in 1985-1987 and 1990-1992, respectively, the cord blood lead level was significantly decreased $(P<0.005)$. It is estimated that such a reduction in cord blood lead from 7.48 to $2.35 \mu \mathrm{g} /$ $\mathrm{dL}$ for each year's cohort of 260,000 newborns in Taiwan might benefit the economics, ranging from US\$8.9 billion to US\$12.1 billion by improving the worker productivity. For the time period from 1985 to 2002, there were consistent transition patterns among the yearly fluctuations of air lead level, leaded gasoline consumption, lead content in gasoline, estimated lead amount emitted from the consumed leaded gasoline, and average cord blood lead levels of the three respective study periods. Additionally, every 0.1 $\mathrm{g} / \mathrm{L}$ reduction in lead content in gasoline might lead to a lowering of cord blood lead level by $1.78 \mu \mathrm{g} / \mathrm{dL}$. Furthermore, at low level of around $2 \mu \mathrm{g} / \mathrm{dL}$, a multiple regression analysis demonstrated that economic status was the most influential factor for cord blood lead variation $(P=0.0061)$ while the maternal working month during her pregnancy was retained in the model with borderline effect $(P=0.0625)$. After accounting for the effect of leaded gasoline on the cord blood lead level, future study to differentiate the primary contributors for the low-level cord blood lead variation around $1-2 \mu \mathrm{g} / \mathrm{dL}$ is warranted.
\end{abstract}

(C) 2004 Elsevier Inc. All rights reserved.

Keywords: Newborn; Cord blood; Lead; Leaded gasoline; Economic status

\footnotetext{
*Corresponding author. Institute of Occupational Medicine and Industrial Hygiene, College of Public Health, National Taiwan University, Rm 1453, No. 1, Sec. 1, Jen-Ai Rd., Taipei 10018, Taiwan, ROC. Fax: + 886-2-2321-5814.

E-mail address: yhh@ha.mc.ntu.edu.tw (Y.-H. Hwang).
}

\section{Introduction}

Lead is not an essential element for the human body, and high blood lead level can result in plumbism or adverse health effects in the hematologic and/or neurologic systems (WHO, 1977). Fetal exposures to lead may happen through placental transfer from pregnant women, which occurs as early as week 12 of 
gestation and continuously throughout pregnancy (Barltrop and Burland, 1969). Further, a lead level greater than $10 \mu \mathrm{g} / \mathrm{dL}$ is reported associated with impairment of neurobehavioral and cognitive development and electrophysiological deficits in children and with reduced gestation and birth weight in infants (Bellinger et al., 1987; Needleman et al., 1984). The Centers for Disease Control and Prevention has, therefore, recommended that the goal of all lead poisoning prevention activities for young children should be the reduction of children's blood lead levels to less than $10 \mu \mathrm{g} / \mathrm{dL}$ (CDC, 1991; WHO, 1995). Furthermore, in a recent study, it was reported that even blood lead levels less than $10 \mu \mathrm{g} / \mathrm{dL}$ may still significantly impair intellectual development in children (Canfield et al., 2003; Rabinowitz et al., 1992). Generally, fetuses, infants, children up to 6 years of age, and pregnant women were the most susceptible to lead toxicity (WHO, 1977). In light of such concerns, the blood lead level, including cord blood lead, is usually used as a biological monitoring indicator for environmental lead pollution in addition to its original role of health condition index (Furman and Lalefi, 2001; Hwang and Wang, 1990; Khan et al., 2001; Mattuck et al., 2001; Niemuth et al., 2001).

Unleaded gasoline has been recognized as the most significant contributor for the decline of human blood lead level in the past decade (Niemuth et al., 2001; Mattuck et al., 2001; Wietlisbach et al., 1995; Neo et al., 2000). In Taiwan, a previous study reported the cord blood lead level in the Taipei area before the introduction of unleaded gasoline in public use (Hwang and Wang, 1990). Since then until the complete cease of leaded gasoline use in February 2000, there has been no thorough study to evaluate the effects of lead elimination in gasoline on the decline of blood lead and its extent with regard to efficiency. It is known that the half-life of blood lead is about 30-40 days (Klaassen, 2001). So, at 1.5 years after the cease of leaded gasoline use in Taiwan, the effect of unleaded gasoline use on the ambient environment must have been totally reflected in blood lead level. Therefore, the present study was conducted to elucidate the extent of cord blood lead level decline from 1985 to 2002, to estimate its transition pattern in the past 2 decades, and to identify possible lead exposure sources other than leaded gasoline.

\section{Materials and methods}

All pregnant women who attended the Taipei Municipal Women and Children Hospital (TMWCH) for newborn delivery between September 2001 and August 2002 were considered the source population of this study. To delineate the effect of the general environmental lead exposure, the target population was further restricted to pregnant women and their husbands without occupational lead exposure. Finally, 1310 women who gave birth to new babies in this study hospital met the recruiting criteria and 185 of them were randomly selected to participate in this study. After being informed about the purpose and the potential risk of this study, all study candidates were required to sign a statement of consent prior to being enrolled in this study. For each delivery of a study subject, $5-10 \mathrm{~mL}$ of umbilical cord blood was collected in a metal-free tube (BD VACUTAINER EDTA; $\mathrm{K}_{3}$ EDTA) and stored at $4{ }^{\circ} \mathrm{C}$ until further analysis. However, among these 185 randomly selected subjects, 1 woman not living in the Taipei area during her pregnancy was excluded from further analysis in this study. Each cord blood sample was analyzed in duplicate by atomic absorption spectrometry with graphite furnace (Perkin-Elmer 5100). For precision requirements, the discrepancy between each pair of duplicates was less than $10 \%$ in all cases. For quality assurance, the analytical system was calibrated with standards of known lead levels in bovine blood, which were obtained from the blood lead proficiency program, Centers for Disease Control and Prevention (CDC, 2002). In addition, our laboratory has participated successfully in the interlaboratory and external quality control program of the CDC and was accredited for blood lead determination in the past 15 years.

Questionnaires were administered through personal interviews, with incomplete data being collected by telephone interviews, by three well-trained interviewers to collect demographic data, reproductive and medical histories, information pertinent to occupational exposure to lead, cigarette smoking, alcohol consumption, use of traditional Chinese medicine, etc.

In addition, information on sequential changes of lead content in gasoline and yearly sales of leaded/unleaded gasoline amounts was obtained from the China Petroleum Co., which was the only wholesaler in Taiwan during the study period. Meanwhile, monthly average atmospheric lead concentration for the local area was obtained from the Environmental Protection Administration (EPA) of the Republic of China.

For detailed before-and-after comparison, the cord blood lead levels obtained in two previous studies were also employed in the present study to illustrate the trend of cord blood lead level changes. One study used the same hospital, i.e., TMWCH, to collect cord blood samples between September 1985 and October 1987 (Hwang and Wang, 1990), while the other study was based on another hospital in the same study area, with annual delivery of about 2700 newborns, to collect cord blood samples from October 1990 to April 1992 (Taiwan EPA, 1992). Cord blood lead samples obtained from these two previous studies were analyzed for lead content at the same laboratory as used in the present study. 
Statistical methods used in the present study included univariate analysis, Student's $t$ tests, correlation analysis, and linear regression. All were performed on the Statistical Analysis System package (SAS, 1998).

\section{Results}

Table 1 shows the demographic data for the study subjects recruited in the present study period; 184 eligible newborns were randomly sampled with cord blood successfully obtained. Average ages of their parents were $33.6 \pm 4.4$ years for the fathers and $30.9 \pm 4.2$ years for the mothers. About half of parents, $48.4 \%$ and $54.9 \%$ for the fathers and the mothers, respectively, were educated at the college level with $32.1 \%$ and $36.4 \%$ for the fathers and the mothers at the senior high school level. About $40.9 \%$ of the fathers were smokers while only $3.3 \%$ of the mothers smoked. With regard to drinking alcohol, only a small portion $(16.8 \%)$ of the fathers drink regularly and none of the mothers reported doing so. With respect to occupational chemical exposure at work, $20.1 \%$ of the fathers and $12.5 \%$ of the mothers reported having such an experience. There was an average of $0.86 \pm 0.80$ children

Table 1

Demographics of newborns' parents and families, TMWCH, 20012002

\begin{tabular}{|c|c|c|c|}
\hline & Father & Mother & Total \\
\hline$N$ & 184 & 184 & 368 \\
\hline Age, years & $33.6 \pm 4.4$ & $30.9 \pm 4.2$ & $32.3 \pm 4.5$ \\
\hline \multicolumn{4}{|l|}{ Education (\%) } \\
\hline$\leqq$ Junior high & $9(4.8)$ & $7(3.8)$ & $16(4.3)$ \\
\hline Senior high & $59(32.1)$ & $67(36.4)$ & $126(34.2)$ \\
\hline College & $89(48.4)$ & $101(54.9)$ & $190(51.6)$ \\
\hline$\geqq$ Graduate & $27(14.7)$ & $9(4.9)$ & $36(9.8)$ \\
\hline \multicolumn{4}{|l|}{ Smoke $(\%)$} \\
\hline Yes & $74(40.9)$ & $6(3.3)$ & $80(21.7)$ \\
\hline No & $110(59.1)$ & $178(96.7)$ & $288(78.3)$ \\
\hline \multicolumn{4}{|l|}{ Alcohol consumption } \\
\hline Yes & $31(16.8)$ & $0(0.0)$ & $31(8.4)$ \\
\hline No & $153(83.1)$ & $184(100.0)$ & 337 (91.6) \\
\hline \multicolumn{4}{|l|}{ Chemical exposure } \\
\hline Yes & $34(18.5)$ & $14(7.6)$ & $48(13.0)$ \\
\hline No & $150(81.5)$ & $170(92.4)$ & $320(87.0)$ \\
\hline Child at home, $<7$ years old & & & $0.86 \pm 0.80$ \\
\hline \multicolumn{4}{|l|}{ Family monthly income, US\$* } \\
\hline$<\mathrm{US} \$ 600$ & & & $28(15.3)$ \\
\hline US\$600-1200 & & & $73(39.9)$ \\
\hline US\$1200-2400 & & & $60(32.8)$ \\
\hline$>$ US\$2400 & & & $22(12.0)$ \\
\hline Cord blood lead level, $\mu \mathrm{g} / \mathrm{dl}$ & & & $2.35 \pm 1.12$ \\
\hline
\end{tabular}

*Only 183 families reported their family monthly income. in each family. The monthly family incomes were mostly at the level of US\$600-1200 (39.9\%), followed by the level of US $\$ 1200-2400$ (32.8\%). The cord blood lead level of the newborns in the Taipei area during the present study period of 2001-2002 averaged $2.35 \pm 1.12 \mu \mathrm{g} / \mathrm{dL}$.

Table 2 presents the correlation matrix of the cord blood lead level with the variables of concern for the general background lead exposure. Cord blood lead level was found significantly and negatively associated with the number of various facilities owned by the family, such as air conditioner, video and audio settings, and leisure facility - a compound variable made by combining the family owned facilities together as a new variable, i.e., air conditioner, video and audio settings, and piano. These variables are usually considered alternative indicators for family social economic status. Other variables in Table 2 did not show any significant association with the cord blood lead level. Nevertheless, although not at a significant level, possession of a house, car, and piano is consistently shown to have a negative association with the cord blood lead level. Meanwhile, during the period of pregnancy, working hours of both parents, months of maternal working during pregnancy, parental smoking and alcohol drinking, and parental occupational exposure to chemicals and dust/odor were indicated to have positive relationships to the cord blood lead level. Multiple regression analysis was then performed to further explore the relationship of cord blood lead level with those predictors listed in Table 2 . Results of backward stepwise regression analysis are shown as the following:

$$
\begin{gathered}
\text { Cord blood lead level, } \mu \mathrm{g} / \mathrm{dL} \\
=2.459-0.153 \text { Leisure facility } \\
+0.099 \text { months of maternal } \\
\text { working during her pregnancy. }
\end{gathered}
$$

It is clearly illustrated that social economic status represented by the leisure facility was the most influential factor for cord blood lead level in the negative direction $(P=0.0061)$ while the months of maternal working during her pregnancy was kept in the model with borderline effect $(P=0.0625)$.

Fig. 1 presents the monthly fluctuations of cord blood lead level in the Taipei area for the three study periods. The cord blood levels decreased significantly from the average of $7.48 \pm 2.25 \mu \mathrm{g} / \mathrm{dL}$ for the 1985-1987 study period to $3.28 \pm 1.52 \mu \mathrm{g} / \mathrm{dL}$ for the 1990-1992 study period and eventually down to $2.35 \pm 1.12 \mu \mathrm{g} / \mathrm{dL}$ for the current 2001-2002 study period. Mean cord blood level of the 1985-1987 study period was extremely different from those of the latter two study periods $(P<0.0001)$, while these latter two study periods themselves also differed from each other significantly $(P=0.0014)$. 


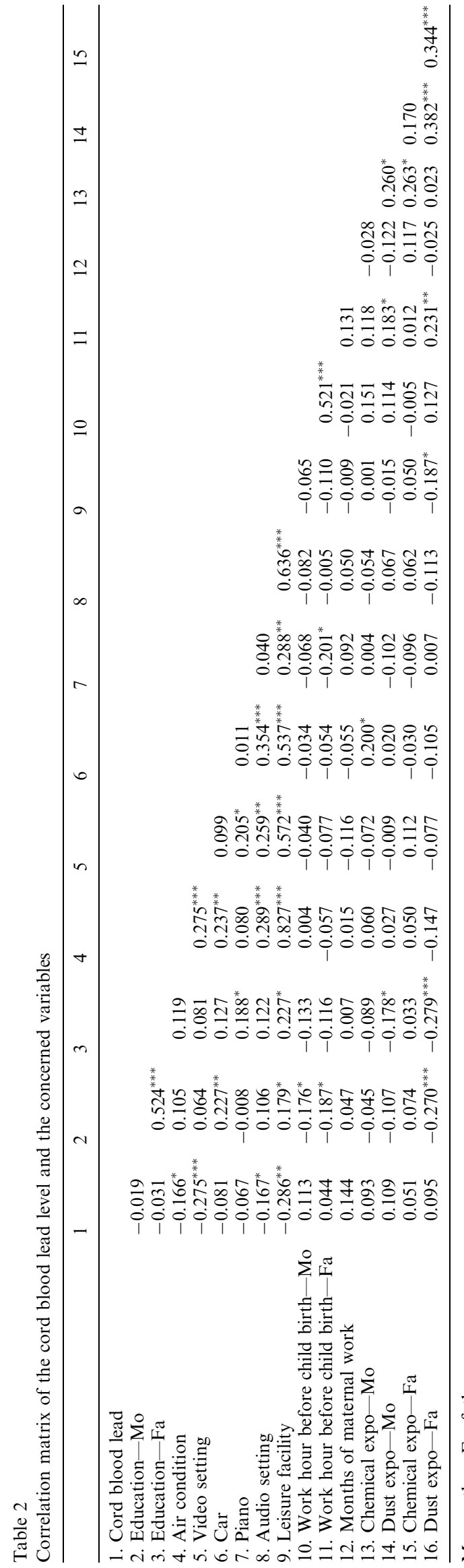

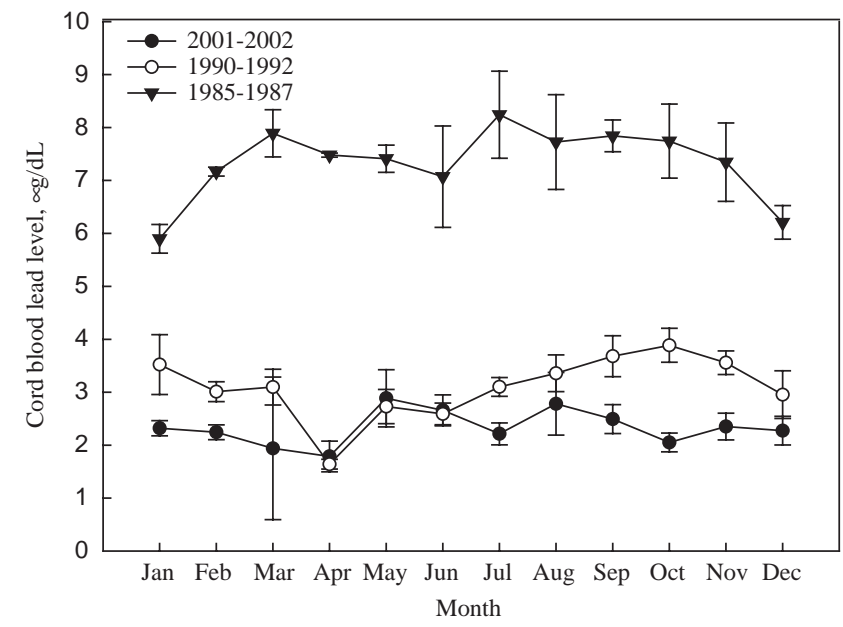

Fig. 1. Fluctuation of cord blood lead level by month for newborns in Taipei area at three study periods.

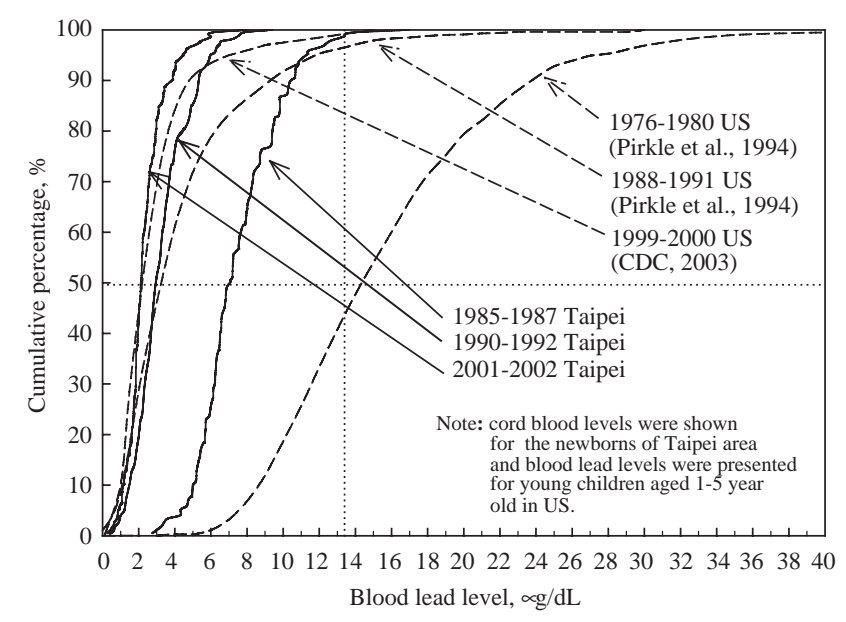

Fig. 2. Cumulative percentage by blood level for the newborns in Taipei area and the children aged 1-5 years old of the United States.

However, no substantial seasonal variation was observed within each of the three study periods.

Fig. 2 illustrates cumulative percentages of the cord blood lead levels obtained from the present and the previous study periods in the Taipei area and the blood lead levels of young children aged 1-5 years in the United States in various years. As mentioned before, the cord blood lead levels in the Taipei area decreased substantially from 1985 to 2002. A similar significant decreasing trend has also been found for the blood lead levels of young children aged 1-5 years in the United States in recent decades, i.e., medians of $15.0 \mu \mathrm{g} / \mathrm{dL}$ in the 1976-1980 survey, $3.7 \mu \mathrm{g} / \mathrm{dL}$ in the $1988-1991$ survey, and $2.2 \mu \mathrm{g} / \mathrm{dL}$ in the $1999-2000$ survey (Pirkle et al., 1994; CDC, 2003). It is noted that the magnitude of decrement in blood lead level was more significant for the young children aged 1-5 years in the United States between 1981 and 2001, i.e., a difference of $11.8 \mu \mathrm{g} / \mathrm{dL}$ in 
median, than that in the cord blood lead level of newborns in the Taipei area between 1985 and 2002, i.e., a difference of $4.84 \mu \mathrm{g} / \mathrm{dL}$ in median $(5.13 \mu \mathrm{g} / \mathrm{dL}$ in mean).

Fig. 3 presents the yearly fluctuations of air lead levels, leaded gasoline consumption, lead content in gasoline, and estimated lead amount emitted from gasoline consumed from 1984 to 2002, along with the average cord blood lead levels of the three respective study periods. For air lead level, this figure presents the fluctuations of yearly air lead levels by averaging each year's monthly air lead reports from all the monitoring sites within the city of Taipei. There was an obvious lowering in air lead level during the observation period of 1984-2002 by a reduction percentage of about $91 \%$ $\left(4.7-0.3 \mu \mathrm{g} / \mathrm{m}^{3}\right)$. However, an elevation in air lead level was found during the time period of 1987-1993. For leaded gasoline consumption, the total amount in sales reached the maximum in 1989 of $1,123,016 \mathrm{~kL}$ and then decreased steadily until the leaded gasoline use was completely ceased in January 2000 . With regard to the lead content in leaded gasoline, the lead concentration was substantially reduced from 0.7 to $0.34 \mathrm{~g} / \mathrm{L}$ between 1982 and 1983. Another sharp reduction from 0.34 to $0.12 \mathrm{~g} / \mathrm{L}$ occurred between 1986 and 1988. Then the lead concentration in leaded gasoline was continuously lowered until the complete cease of leaded gasoline use in early 2000. Meanwhile, estimated lead emitted from consumed gasoline was calculated by timing the specific lead concentration in various gasoline products with the gasoline amount consumed in the respective year. It is clearly demonstrated that the estimated lead amount emitted from the consumed gasoline dropped promptly from $255,624 \mathrm{~kg} /$ year in 1984 to $30,312 \mathrm{~kg} /$ year in 1994 and finally down to $12 \mathrm{~kg}$ /year in January 2000, when the leaded gasoline was totally removed from market. In Fig. 3, the average cord blood lead levels of the newborns during the three respective study periods, with $95 \%$ confidence intervals, are also marked on this plot. By eyeball check, the decreasing trend of cord blood level was pretty close to those trends for air lead level and estimated lead amount emitted from the consumed gasoline. Table 3 presents the correlation matrix of yearly lead content in gasoline, consumed leaded gasoline, estimated lead emitted from gasoline, and air lead level during the study period of 1985-2002 in the Taipei area. These four parameters were highly correlated with each other with the highest correlation coefficients being between the estimated lead emitted from gasoline and the lead content in gasoline (0.963) and between the estimated lead emitted from gasoline and the air lead level (0.953). Furthermore, lead content
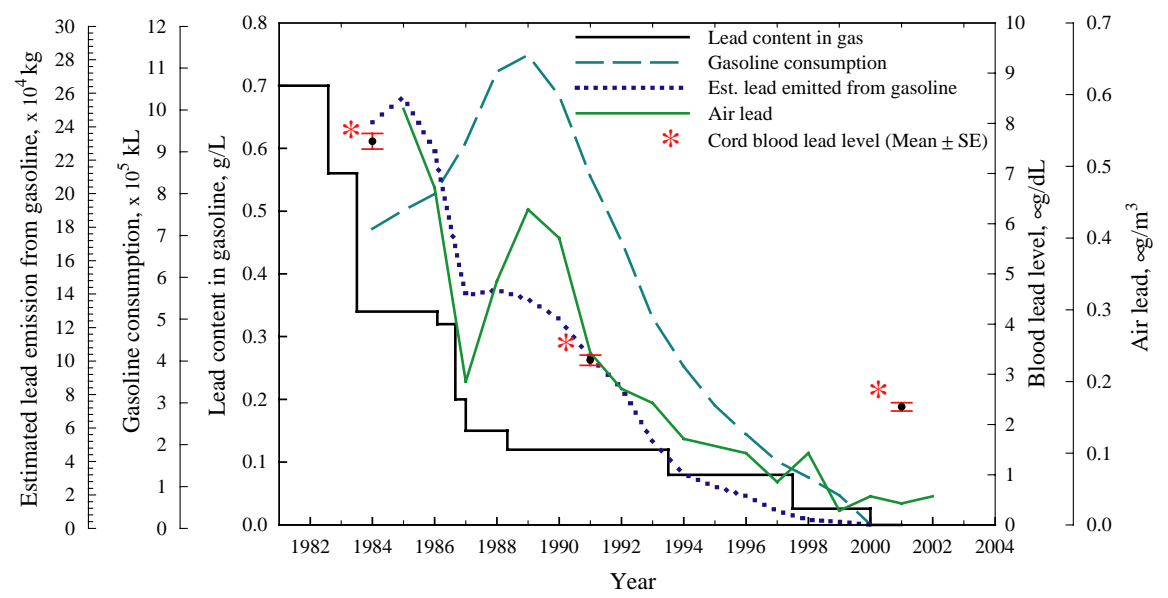

Fig. 3. Fluctuation of cord blood lead level, lead content in gasoline, gasoline consumption, estimated lead emission from gasoline and air lead during the study periods.

Table 3

Correlation matrix of yearly lead content in gasoline, consumed leaded gasoline, estimated lead emitted from gasoline, and air lead level during the study period of 1985-2002 in the Taipei area

\begin{tabular}{llll}
\hline & 1 & 2 & 3 \\
\hline 1. Lead content in gasoline $(\mathrm{g} / \mathrm{L})$ & & & \\
2. Consumed leaded gasoline $(\mathrm{kL} /$ year $)$ & $0.664(0.0019)$ & $0.779(<0.0001)$ & $0.832(<0.0001)$ \\
3. Estimated lead emitted from gasoline $(\mathrm{kg} /$ year $)$ & $0.963(<0.0001)$ & $0.869(<0.0001)$ & $0.953(<0.0001)$ \\
4. Air lead level $\left(\mu \mathrm{g} / \mathrm{m}^{3}\right)$ &
\end{tabular}

If lead content in gasoline changed in a year, that year's lead content was estimated by weighing the months that the specific lead contents were applied in gasoline. 
in gasoline was used in a regression model as an example to predict the cord blood level. The following is the result of this analysis:

Cord blood lead level, $\mu \mathrm{g} / \mathrm{dL}$

$=2.163+17.82$ Lead content in gasoline, $\mathrm{g} / \mathrm{L}$.

With this model, lead content in gasoline was demonstrated to have a significant effect on the cord blood lead change $(P<0.0001)$ with high model $r^{2}$ of 0.5845 .

\section{Discussion}

Cord blood lead level was intended to be used as a pollution index to monitor the environmental lead exposure in the present study. With it, lead exposure from various routes of intake would all be comprehensively reflected in the blood lead content. Since the blood lead reflects the exogenous lead exposure that was already absorbed into and so distributed inside the body, its temporal fluctuations would more closely reflect the effect of yearly lead exposure with newborns as receptors. Such merit enhances the choice of this kind of biological marker for environmental lead exposure in the present study.

In this study, it has been demonstrated that cord blood lead of newborns, from 1985 to 2002, has been effectively lowered by $5.13 \mu \mathrm{g} / \mathrm{dL}(68.6 \%)$ after the cease of leaded gasoline use in Taipei. Since the present study was able to obtain the cord blood levels in 1984-1985, just before the commencement of the significant lowering of the lead content in gasoline and the introduction of unleaded gasoline in the commercial sales in 1986, and in 2001-2002, right after the cease of leaded gasoline use in Taiwan in January 2000, it is believed that the reduction effect on cord blood lead level by ceasing leaded gasoline use could be thoroughly reflected in the present study. In addition, during the observation period, there was no eradication campaign launched in Taiwan for environmental lead exposure except for the gradual reduction of gasoline lead content and the continuous increase in the proportion of unleaded gasoline use until all leaded gasoline was totally eliminated from the market. Accordingly, the magnitude of the reduced cord blood lead level, i.e., $5.13 \mu \mathrm{g} / \mathrm{dL}$, in the present study could almost all be attributed to the effect of ceasing leaded gasoline use.

The relationship between increased blood lead at lowlevel concentration and decreased IQ has long been of concern. A previous study, with children blood lead concentrations varying up to $20 \mu \mathrm{g} / \mathrm{dL}$, estimated a decline of 5.8 points in IQ with an increase in blood lead concentration from 10 to $20 \mu \mathrm{g} / \mathrm{dL}$ (Bellinger et al., 1992). Another previous meta-analysis concluded that there was an IQ decline by 2.6 points for an increase in lead concentration from 10 to $20 \mu \mathrm{g} / \mathrm{dL}$ (Schwartz, 1994a). Furthermore, any possible adverse effect of the very low blood lead concentration, less than $10 \mu \mathrm{g} / \mathrm{dL}$, is of more concern for the general newborns without parental occupational lead exposure in the present study. Unfortunately, a recent study did further extend the familiar relation between increased blood lead concentration and decreased IQ to blood lead concentration below $10 \mu \mathrm{g} / \mathrm{dL}$ (Canfield et al., 2003). In that study, a smoothed curve summarizing their data showed a decline in IQ at both 3 and 5 years of age by 7.4 points as lifetime average blood lead concentrations increased from 1 to $10 \mu \mathrm{g} / \mathrm{dL}$, and a further decline of approximately 2 points associated with a increase from 10 to $20 \mu \mathrm{g} / \mathrm{dL}$. According to these previous studies, blood lead level below $10 \mu \mathrm{g} / \mathrm{dL}$ seems more sensitive to IQ performance. In the present study, if we simply consider the cord blood lead level to be the blood lead level for the young children of 1-5 years old and interpolate the IQ change based on a decrease of 7.4 points from blood lead level of 1 to $10 \mu \mathrm{g} / \mathrm{dL}$, we may estimate an IQ gain by 4.2 points based on the lowering of cord blood lead level from $7.48 \pm 2.25 \mu \mathrm{g} / \mathrm{dL}$ in $1985-1987$ down to $2.35 \pm 1.12 \mu \mathrm{g} / \mathrm{dL}$ in $2001-2002$. This IQ increase of 4.2 points corresponding to the $5.13-\mu \mathrm{g} / \mathrm{dL}$ decrease in blood lead level is a conservative estimate compared to the finding in a previous local study with a small sample size of kindergarten students, who gained 11.7 points in IQ as their blood lead level decreased by $6.9 \mu \mathrm{g} / \mathrm{dL}$ (Soong et al., 1999). Even with such a conservative way to estimate IQ improvement, considering the entire population as a whole, this improvement by 4.2 points in IQ is a great achievement with regard to social cost and manpower development. According to the previous studies' estimates that each IQ point raises worker productivity 1.76-2.38\% (Grosse et al., 2002; Salkever, 1995; Schwartz, 1994b) and the given lifetime earnings of US $\$ 465,480$ for each newborn in 2001 dollars based on the national income per capita (DGBAS, 2001), the estimated economic benefit for each year's cohort of 260,000 newborns in Taiwan (DOH, 2001) ranges from US $\$ 8.9$ billion to $\$ 12.1$ billion. However, as emphasized earlier, low-level blood lead is more sensitive to the IQ performance of the young children aged 1-5 years. Therefore, even though the cord blood lead level has been lowered to $1-2 \mu \mathrm{g} / \mathrm{dL}$, continuous efforts to eliminate environmental lead exposure are worthy and necessary to prevent succeeding generations from experiencing early mental deteoriation.

Some previous studies have indicated that the cord blood lead level is about $55-92 \%$ of the mother's blood lead level (Ernhart, 1992; Furman and Lalefi, 2001; Gardella, 2001). Based on this, for the viewpoint of comparability, we may convert the cord blood lead level to the concurrent adult/child blood lead level with an appropriate converting factor. For instance, given a 
ratio of $55-92 \%$ for the cord blood lead level to the maternal blood lead level, we may estimate the average maternal blood lead levels to range around 8.13-13.45, $3.56-5.96$, and $2.55-4.27 \mu \mathrm{g} / \mathrm{dL}$, respectively, for the study periods of 1985-1987, 1990-1992, and 2001-2002 in the Taipei area, based on the respective average cord blood lead level of $7.48,3.28$, and $2.35 \mu \mathrm{g} / \mathrm{dL}$ at the different time periods. In contrast to this, a previous survey in Taiwan by the local health authority has reported a substantial decline in blood lead level for the adult people in Taipei from $7.64 \mu \mathrm{g} / \mathrm{dL}$ in 1994 to $3.89 \mu \mathrm{g} / \mathrm{dL}$ in 1997 (DOH, 1998). Considering the corresponding time period, the average maternal blood lead level estimated by adjusting the cord blood lead level in the present study seems to be very close to, but a little bit less than, that found in this local authority's survey. Such a difference might be reasonable since this local authority's survey, unlike the present study excluding subjects with potential occupational lead exposure, involved all the people with or without leadrelated work. Also, not reporting for females only, this local authority's survey also involved males, who are thought to have higher blood lead level than females (Liou et al., 1996a; Pirkle et al., 1994; CDC, 2003). On the other hand, a previous study also reported a significant decreasing trend of blood lead levels for lead battery workers in Taiwan from $34.7 \pm 15.0 \mu \mathrm{g} / \mathrm{dL}$ in 1991 down to $23.9 \pm 12.4 \mu \mathrm{g} / \mathrm{dL}$ in 1997 (Chuang et al., 1999). Compared to the aforementioned decrement in maternal blood lead level estimated from the present study during the corresponding time period, such lowering of blood level in lead-related workers between 1991 and 1997 could be, in a great proportion, attributed to the improvement in general environmental lead exposure, i.e., the reduction of leaded gasoline use, rather than the improvement in lead-related work conditions, such as engineering control, exposure management, etc.

By comparison, obviously there was still a great difference between the cord blood lead level of newborns in the Taipei area and the blood lead level of young children aged 1-5 years in the United States in the 1980s and 1990s (Fig. 2). Nevertheless, they were found to finally get closer in the 2000s. In addition to the cease of leaded gasoline use, the most probable explanation for such transition of blood lead level difference between them in the past 2 decades is the history of lead-based paint use. In the United States, pregnant women living in homes built before 1977 undergoing renovation are thought to be at risk for lead exposure from the debris in the dwelling and the surrounding ground resulting from renovations (Needleman, 1992; Gardella, 2001). Therefore, in addition to the source of leaded gasoline, a considerable part of environmental lead pollution was attributed to the distribution of lead-based paint debris from old house renovations. Unlike this well-known situation in the United States, there are few reports of lead pollution originally coming from lead-based paint in Taiwan. This is probably due to the relative short development history in modern life and the limited-leadbased paint use in Taiwan compared to the long history of lead based paint use in the United States, in which urban modernization proceeded earlier and many houses aged 60 years or over were still in use in recent decades (Gardella, 2001). This could explain the big difference between the cord blood lead level of the Taipei area and the children blood lead level of the United States in 1980s and 1990s (Fig. 2). Finally, these two blood lead levels of the different geographical areas get closer in the 2000s when the primary source(s) for environmental lead pollution have been effectively controlled, i.e., leaded gasoline and lead-based paint in the United States (CDC, 2003) and leaded gasoline in Taiwan. Therefore, once these primary environmental lead sources were successfully eradiated in recent decades, the cord blood lead level would continuously go down to the background level and vary in limited range for averages, i.e., $1.5-2.5 \mu \mathrm{g} / \mathrm{dL}$, at different places around the world (Furman and Lalefi, 2001; Mattuck et al., 2001; Pirkle et al., 1994; CDC, 2003; Wietlisbach et al., 1995; Neo et al., 2000).

With regard to the efficacy of reducing lead content in gasoline as a means to reduce cord blood lead level, the regression analysis in the present study indicated that every $0.1-\mathrm{g} / \mathrm{L}$ reduction in lead content in gasoline would result in a $1.78-\mu \mathrm{g} / \mathrm{dL}$ reduction in the cord blood lead level. Even though the underlying relationship between lead content in gasoline and cord blood lead level is complicated and might be substantially affected further by the amount of leaded gasoline consumption and the general traffic and atmospheric situations, there was still a strong association between the reduction of cord blood lead level and the reduction of lead content in gasoline. This finding gives us a hint to explore the association between the lead elimination from the environment, i.e., leaded gasoline and lead-based paint, and the reduction of blood lead level in the United States. Should the annual change of lead content level in gasoline be given, it is possible to differentiate the partial contribution of the reduction of lead content in gasoline on the prevention of environmental lead pollution from the reduction of other lead sources in the environment, such as lead-based paint.

Since the cord blood lead level in the Taipei area has already been reduced to the level of around $2 \mu \mathrm{g} / \mathrm{dL}$, equivalent to that of other countries which have ceased the use of leaded gasoline for years, it is believed that the environmental lead exposure in the study area has also diminished to the currently recognized background level. However, even though the cord blood lead level has been reduced to this low level, its variation was still found to be strongly associated with the familiar social 
economic status in the present study, which mostly involved the leisure facilities owned by the family, such as the air conditioner and video and visual settings at home. But, on the other hand, no such significant associations were observed for the parental education and age, ethnicity, parity, newborn gender, etc. (Table 2). In the present study, the information collected is not appropriate to further explore these two factors' association with the cord blood lead level. Nevertheless, such findings in the present study have already indicated that, even at the low level of cord blood lead level around $2 \mu \mathrm{g} / \mathrm{dL}$, its variation still could be accounted for by the lead sources from the general environment.

Future detailed and comprehensive study to further explore the contributors for the low-level cord blood lead variation is warranted. Among those suggested candidates, lead sources on the roads and/or in the surrounding areas in the general environment are some of the most likely contributors for such variation in lowlevel cord blood lead since the lead souses might be resuspended during daily human activities, especially the heavy traffic, and thus might have led to an increase of lead uptake through inhalation by the parents of those newborns in the present study. Of course, at such a low level around $2 \mu \mathrm{g} / \mathrm{dL}$, the cord blood lead level might also be significantly modified by certain other environmental sources, such as contaminated lead in food and/ or drinking water, etc. With regard to the drinking water, the tap water supplying rate in the Taipei area is very high (almost 100\%). Also, the government forbade the use of leaded pipes more than 20 years ago, and the routine water quality report has never shown lead content in water to exceed the drinking water standard of $50 \mu \mathrm{g} / \mathrm{L}$ (TWNEPA, 1997), with rare cases reported over the detection limit of $1 \mu \mathrm{g} / \mathrm{L}$. Therefore, drinking water is not currently considered to have a significant role in the variation of low-level cord blood lead. With respect to food, under strict quarantine by the local health authority, all food stuffs available for the public must follow the relevant standards for permissible lead content in food ranging from 0.05 to $2.0 \mathrm{ppm}$ to prevent possible food contamination ( $\mathrm{DOH}, 2000)$. So far, no food contamination by heavy metal has been reported locally in recent years. Therefore, food also was thought to be probably not the source of low-level cord blood lead variation. However, since interindividual variation in lead intake through drinking water and/or food is not clearly understood, whether such routes of lead exposure are subtly associated with the low-level cord blood lead still needs to be further explored in the future when the measurement of extremely low levels of lead content in drinking water and food is possible. In addition, in this future study to differentiate the primary lead source for the variation of cord blood lead level at the range of $1-2 \mu \mathrm{g} / \mathrm{dL}$, special attention should also be given to the possible lead content in certain special items, such as herb medicine, nourishing diet, etc. and the individual's sanitation and hygienic habits, etc. (Liou et al., 1996b; Melnyk et al., 2000; Tripathi et al., 1997) to thoroughly elucidate the subtle interaction between trace lead exposure and cord blood lead level variation.

\section{Acknowledgments}

This study was partly supported by the National Science Council, Taiwan, Republic of China (NSC902815-C-002-019-B). We are also grateful to the physicians and nurses of the Department of Gynecology and Obstetrics, Taipei Municipal Women and Children Hospital, who helped to collect cord blood samples and made this study possible.

\section{References}

Barltrop, D., Burland, W.D., 1969. Transfer of lead to the human fetus. In: Mineral Metabolism in Pediatrics. Blackwell Scientific Publications, Oxford, pp. 135-151.

Bellinger, D., Leviton, A., Waternaux, C., Needelman, H., Rabinowitz, M., 1987. Longitudinal analysis of prenatal and postnatal lead exposure and early cognitive development. N. Engl. J. Med. 316, 1037-1043.

Bellinger, D.C., Stiles, K.M., Needleman, H.L., 1992. Low-level lead exposure, intelligence and academic achievement: a long-term follow up study. Pediatrics 90, 855-861.

Canfield, R.L., Henderson, C.R., Cory-Slechta, D.A., Cox, C., Jusko, T.A., Lanphear, B.P., 2003. Intellectual impairment in children with blood lead concentrations below $10 \mu \mathrm{g}$ per deciliter. N. Eng. J. Med. 348 (16), 1517-1526.

CDC, 1991. Preventing lead poisoning in young children: a statement by the Centers for Disease Control. Center for Diseases Control, Atlanta.

CDC, 2002. Blood lead proficiency testing. Centers for Disease Control and Prevention, Atlanta.

CDC, 2003. Second National Report on Human Exposure to Environmental Chemicals. NCEH Pub. No. 03-0022, Centers for Disease Control and Prevention, Atlanta.

Chuang, H.Y., Lee, M.L.T., Chao, K.Y., Wang, J.D., Hu, H., 1999. Relationship of blood lead levels to personal hygiene habits in lead battery workers: Taiwan, 1991-1997. Am. J. Ind. Med. 35, 595-603.

DGBAS, 2001. National Income per Capita, 2001. DirectorateGeneral of Budget, Accounting, and Statistics, Executive Yuan of Republic of China, Taipei, Taiwan.

DOH, 1998. Blood lead report and monitoring system - annual report. Bureau of Quarantine, Department of Health, Taipei, Taiwan, ROC.

DOH, 2000. Law Governing Food Sanitation. Department of Health, Taipei, Taiwan, ROC.

DOH, 2001. Vital Statistics, 2001. Department of Health, Taipei, Taiwan, ROC.

Ernhart, C.B., 1992. A critical review of low-level prenatal lead exposure in the human: 1. Effects on the fetus and newborn. Reprod. Toxicol. 6, 9-19.

Furman, A., Lalefi, M., 2001. Maternal and umbilical cord blood lead levels. Arch. Environ. Health 56 (1), 26-28. 
Gardella, C., 2001. Lead exposure in pregnancy: a review of the literature and argument for routine prenatal screening. Obstet. Gynecol. Surv. 56 (4), 231-238.

Grosse, S.D., Matte, T.D., Schwartz, J., Jackson, R.J., 2002. Economic gains resulting from the reduction in children's exposure to lead in the United States. Environ. Health Perspect. 110 (6), 563-569.

Hwang, Y.H., Wang, J.D., 1990. Temporal fluctuation of the lead level in the cord blood of neonates in Taipei. Arch. Environ. Health 45 (1), 42-45.

Khan, A.H., Khan, A., Ghani, F., Khurshid, M., 2001. Low-level lead exposure and blood lead levels in children: a cross-sectional survey. Arch. Environ. Health 56 (6), 501-505.

Klaassen, C.D., 2001. Casarett \& Doull's Toxicology-The Basic Science of Poisons 6th Edition. McGraw-Hill, New York.

Liou, S.H., Wu, T.N., Chiang, H.C., Yang, G.Y., Yang, T., Wu, Y.Q., et al., 1996a. Blood lead levels in Taiwanese adults: distribution and influencing factors. Sci. Total Environ. 180, 211-219.

Liou, S.H., Wu, T.N., Chiang, H.C., Yang, T., Yang, G.Y., Wu, Y.Q., et al., 1996b. Three-year survey of blood lead levels in 8828 Taiwanese adults. Int. Arch. Occup. Environ. Health 68 (2), 80-87.

Mattuck, R.L., Beck, B.D., Bowers, T.S., Cohen, J.T., 2001. Recent trends in childhood blood lead levels. Arch. Environ. Health 56, 536-541.

Melnyk, L.J., Berry, M.R., Sheldon, L.S., Freeman, N.C., Pellizzari, E.D., Kinman, R.N., 2000. Dietary exposure of children in leadladen environments. J. Expo. Anal. Environ. Epidemiol. 10 (6), 723-731.

Needleman, H.L., 1992. Human Lead Exposure. CDC Press, Boca Raton, FL.

Needleman, H.L., Rabinowitz, M., Leviton, A., Linn, S., Schoenbaum, S., 1984. The relationship between prenatal exposure to lead and congenital anomalies. J. Am. Med. Assoc. 251 (22), 2956-2959.

Neo, K.S., Goh, K.T., Sam, C.T., 2000. Blood lead levels of a population group not occupationally exposed to lead in Singapore. Southeast Asian J. Trop. Med. Public Health 31 (2), 295-300.
Niemuth, N.A., Wood, B.J., Schultz, B.D., 2001. Estimated change in blood lead concentration in control populations. Arch. Environ. Health 56 (6), 542-551.

Pirkle, J.L., Brody, D.J., Gunter, E.W., Kramer, R.A., Paschal, D.C., Flegal, K.M., Matle, T.D., 1994. The decline in blood lead levels in the United States, the national health and nutrition examination surveys (NHANES). J. Am. Med. Assoc. 272 (4), 284-292.

Rabinowitz, M.B., Wang, J.D., Soong, W.T., 1992. Apparent threshold of lead effect on child intelligence. Bull. Environ. Contam. Toxicol. 48, 688-695.

SAS, 1998. SAS/STAT User's Guide, Version 6.12. SAS Institute Inc., Cary, NC.

Salkever, D.S., 1995. Updated estimate of earnings benefits from reduced exposure of children to environmental lead. Environ. Res. $70,1-6$.

Schwartz, J., 1994a. Low-level lead exposure and children's IQ: a meta-analysis and search for a threshold. Environ. Res. 65, 42-45.

Schwartz, J., 1994b. Social benefits of reducing lead exposure. Environ. Res. 66, 105-124.

Soong, W.T., Chao, K.Y., Jang, C.S., Wang, J.D., 1999. Long-term effect of increased lead absorption on intelligence of children. Arch. Environ. Health 54 (4), 297-301.

Taiwan EPA, 1992. Air pollution monitoring in Taipei City with cord blood lead level. EPA-81-E3K1-09-02, Environmental Protection Agency, Taipei, ROC.

Tripathi, R.M., Raghunath, R., Krishnamoorthy, T.M., 1997. Dietary intake of heavy metals in Bombay city, India. Sci. Total Environ. 208 (3), 149-159.

TWNEPA, 1997. Drinking Water Management Act, 1997. Environmental Protection Agency, Taipei, Taiwan, ROC.

WHO, 1977. Environmental Health Criteria 3: Lead. World Health Organization, Geneva.

WHO, 1995. International Programme on Chemical Safety: Inorganic lead. Environment Health Criteria No. 165. World Health Organization, Geneva.

Wietlisbach, V., Rickenbach, M., Berode, M., Guillemin, M., 1995. Time trend and determinants of blood lead levels in a Swiss population over a transition period (1984-1993) from leaded to unleaded gasoline use. Environ. Res. 68 (2), 82-90. 